\title{
The Performance Evaluation Research of Governmental Financial Investment in Science and Technology in Shandong Province Base on DEA
}

\author{
Liang Feng \& Pan Yao \\ School of Information and technology, Shandong women's university, P. R. china
}

\begin{abstract}
The academic circle and the government have paid close attention to the performance evaluation of governmental financial investment in science and technology. Having reviewed relevant literature home and abroad over the past years, the author has established an effective index system for such evaluation in line with the specific conditions of Shandong province. Besides, the author adopted Data Envelopment Analysis (DEA) to evaluate Shandong province's governmental financial investment in science and technology between 1998 and 2011. The author came up with such finding that in general the performance evaluation of governmental financial investment in science and technology of Shandong province was relatively effective, but problems remained such as the rather low proportion of governmental financial investment in science and technology in the overall provincial financial budget, and the deficient science and technology output, etc.
\end{abstract}

KEYWORD: DEA; governmental financial investment in science and technology; performance evaluation

\section{INTRODUCTION}

In the 1950s, Solow put forward unprecedented suggestion that technology should be integrated to capital and labor, on which basis he proposed the concept of Total Factor Productivity (TFP). Since then, people have been attracted to the increasingly important role that science and technology play in propelling economic growth. In history, almost every science and technology breakthrough has accelerated the development of economy. To many countries, the strengthening of scientific and technological innovation is as important as a national strategy. As a result, considering investment in science and technology as a strategic investment, an increasing number of countries have enlarged their financial investment in science and technology by a large margin. In addition, these countries have deployed in advance and given momentum to the development of front-tier and strategic industries, carried out major science and technology plans. With these measures, countries look forward to sharpening their innovation and international competence.

Since the implementation of reform and opening up to the outside world, we have witnessed the growingly important role that science and technology have played in the development of economic and social progress. Being a driving force, science and technology have been vigorously contributed to the rapid development of China over the past 30 years. The advance of science and technology must be based on adequate investment in science and technology, in which governmental financial investment assumes an important role. In particular, with regard to China's relatively backward scientific and technological situation, the financial investment from the government is critical. Without investment, there would have been no science and technology advance. Being an important part of investment, governmental investment in science and technology plays a guiding and exemplary role. Nevertheless, given the fact that governmental financial investment constitutes one part of governmental financial budget expenditure and comes from revenue, it should be effectively governed and given proper evaluation.

\section{LITERATURE REVIEW}

At the beginning of the 20th century, economists in the west began to study the relationship between science and technology investment and economic growth. According to Solow[1] (1957), in an age featuring unstable economy, advance in technology is vital to economic growth. Based on such 
reasoning, he built up a growth pattern. As research furthered, there emerged an endogenous theory holding that science and technology are the driving force. Such theory maintains that since technology is endogenous in economy system and is the core of economic growth, the increase of investment in science and technology will expedite the development of economy. The supporters of Solow's theory included such famous scholars as Paul Romer (1986), Griliches (1986), Hall and Mairesse (1995), Nadir, Mamuneas (1995), Aghio and Howitt (1992). According to them, the more investment in $\mathrm{R} \& \mathrm{D}$, the faster the economic development. Meanwhile, the investment in public $\mathrm{R} \& \mathrm{D}$ will promote industrial development, encourage enterprises to make more investments in science and technology research so as to increase the growth rate of economy. However, Jones (1995) and Segerstrom (1998) argued that Romer's research was imperfect for the latter's research was based on the hypothesis of economics of scale. Through intensive research, Jones and Segerstrom found that although increasing governmental allowance granted to the development of science and technology resulted in a growing number of $\mathrm{R} \& \mathrm{D}$ personnel, it had no positive longterm effect on economic development. To argue against Jones and Segerstron, Howitt (1999) improved his economies of scale, which later supported the conclusion that governmental allowance granted to science and technology was conducive to the long-term development of economy.

Overseas scholars and experts' research in performance evaluation of governmental financial investment in science and technology is also worth our attention. Reflecting government's expanding fiscal and monetary policy, governmental investment in science and technology was found to result in a crowding out effect or a complementary effect. Based on their review of plenty of empirical literature, David, Hall and Toole( 1999) found that as far as industry or country was concerned only two out of 14 experiment studies believed that governmental financial investment in science and technology would crowd out enterprises' own investment in this aspect, and as far as enterprise was concerned nine out of 19 empirical studies believed that governmental financial investment in science and technology would play a complementary role, in other words, the government would partially or wholly crowd out enterprises' investment in this aspect. Based on his research with the support of Panel Data Model, Lach(2001) argued that governmental financial investment in science and technology would not completely crowd out enterprises' investment in this aspect. According to Guellec and Pottlesberge(2000) , governmental financial investment in science and technology would have a $U$ pattern effect on the development to science and technology, and the incentive effect of governmental financial investment in science and technology on the development of science and technology would be maximal on the condition that the former was in a moderate scale, while it would produce a crowding out effect if its scale was extremely large.

Recently, Chinese scholars and experts have addressed the relationship between governmental financial investment in science and technology and the growth of economy, the model and the methods of performance evaluation of governmental financial investment in science and technology. Xie, Fuquan, and Ren, Hao(2006) established a performance evaluation system and calculated the ratio between input and output of science and technology projects through the instrument of fuzzy mathematics. Wang, Guiqiang, and Zhang, Jing( 2006) proposed the concept of Index Mark, in other words, using substitute variable instead of certain index to carry out measuring, so as to overcome the problem that it was difficult to obtain data for the evaluation of governmental financial investment in science and technology. Xie, Hong(2007) used analytical hierarchy process(AHP) and index group that could properly reflect the benefit out of investment in science and technology to perform exemplary performance evaluation of governmental financial investment in science and technology. Kao, Yanming (2009) used principal component analysis to construct an evaluation model and introduced empirical analysis in the course of constructing index systems and evaluation models, and put forward pertinent countermeasures and suggestions. Zhao, Liyu and Shi, Ping (2008) used co-integration method to test the performance evaluation of governmental financial investment in science and technology and target strength. Ji, Hongen(2009) used BC2 model of DEA to evaluate the ratio between input and output of science and technology endeavors among decision-making units of 30 provinces in China in 2006.Meanwhile, he evaluated the effectiveness of science and technology endeavors of decision-making units in East China, West China and Central China.

\section{THE CURRENT STATE OF GOVERNMENTAL FINANCIAL INVESTMENT IN SCIENCE AND TECHNOLOGY IN SHANDONG PROVINCE}

Over the past years, realizing the importance of science and technology advance and innovation in the accomplishment of industrialization building a moderately better-off society, Shandong provincial government gave priority to science and technology in its provincial rejuvenation undertaking. Hence, the provincial government strengthened its financial 
investment in science and technology, achieving great progress in science and technology.

To develop a full picture of the governmental financial investment in science and technology in Shandong province, we need to understand the following aspects.

1) The governmental financial grant to science and technology maintained a rapid increase

Before 2007, Shandong province's governmental financial grant to science and technology was mainly made up of funds for public science and technology undertakings and other relevant funds. However, after that year, as statistical caliber changed, the grant has been collectively called funds for science and technology undertakings.

Table 1. 1993-2012 Statistics of Shandong Province's Government Financial Grant (in the unit of 10,000 RMB)

\begin{tabular}{|c|c|c||c|c|c|}
\hline $\begin{array}{c}\text { Fiscal } \\
\text { Year }\end{array}$ & Grant & $\begin{array}{c}\text { Year-on-year } \\
\text { increase }\end{array}$ & $\begin{array}{c}\text { Fiscal } \\
\text { Year }\end{array}$ & Grant & $\begin{array}{c}\text { Year-on-year } \\
\text { increase }\end{array}$ \\
\hline 1993 & 32485 & $20.27 \%$ & 2003 & 199045 & $4.81 \%$ \\
\hline 1994 & 39415 & $21.33 \%$ & 2004 & 223770 & $12.42 \%$ \\
\hline 1995 & 46863 & $18.90 \%$ & 2005 & 270670 & $20.96 \%$ \\
\hline 1996 & 61421 & $31.07 \%$ & 2006 & 367127 & $35.64 \%$ \\
\hline 1997 & 81334 & $32.42 \%$ & 2007 & 464073 & $26.41 \%$ \\
\hline 1998 & 98337 & $20.91 \%$ & 2008 & 571333 & $23.11 \%$ \\
\hline 1999 & 115206 & $17.15 \%$ & 2009 & 628783 & $10.06 \%$ \\
\hline 2000 & 131002 & $13.71 \%$ & 2010 & 843643 & $34.17 \%$ \\
\hline 2001 & 160685 & $22.66 \%$ & 2011 & 1086163 & $28.75 \%$ \\
\hline 2002 & 189917 & $18.19 \%$ & 2012 & 1249751 & $15.06 \%$ \\
\hline
\end{tabular}

* Data source: Shandong Statistic Yearbook

It is seen from Table 1 that over the past twenty years except for the year of 2003 Shandong province has maintained a rapid increase of governmental financial grant to science and technology, with yearly increase up to $20.02 \%$.

2) The governmental financial investment in science and technology accounted for a rather low proportion in the overall financial budget.

There was a positive correlation relationship between investment in science and technology and economic growth, which indicates that the increase of investment in science and technology would to some extent lead to the growth of economy. However, so far, Shandong province's governmental financial investment in science and technology has only accounted for a small proportion of the total financial budget expenditure, which to some extent indicates that such investment remains to be improved.
Table2 1993-2012 Statistics of Shandong Province's Governmental Financial Budget Expenditure (in the unit of 10,000 RMB)

\begin{tabular}{|c|c|c|}
\hline Fiscal year & $\begin{array}{c}\text { Financial budget } \\
\text { expenditure }\end{array}$ & $\begin{array}{c}\% \text { of the total financial } \\
\text { budget expenditure }\end{array}$ \\
\hline 1993 & 1883646 & $1.72 \%$ \\
\hline 1994 & 2187683 & $1.80 \%$ \\
\hline 1995 & 2758656 & $1.70 \%$ \\
\hline 1996 & 3589836 & $1.71 \%$ \\
\hline 1997 & 4233342 & $1.92 \%$ \\
\hline 1998 & 4878175 & $2.02 \%$ \\
\hline 1999 & 5500034 & $2.09 \%$ \\
\hline 2000 & 6130774 & $2.14 \%$ \\
\hline 2001 & 7537781 & $2.13 \%$ \\
\hline 2002 & 8606484 & $2.21 \%$ \\
\hline 2003 & 10106395 & $1.97 \%$ \\
\hline 2004 & 11893716 & $1.88 \%$ \\
\hline 2005 & 14662271 & $1.85 \%$ \\
\hline 2006 & 18334400 & $2.00 \%$ \\
\hline 2007 & 22618495 & $2.05 \%$ \\
\hline 2008 & 27046613 & $2.11 \%$ \\
\hline 2009 & 32676716 & $1.92 \%$ \\
\hline 2010 & 41450320 & $2.04 \%$ \\
\hline 2011 & 50020701 & $2.17 \%$ \\
\hline 2012 & 59045188 & $2.12 \%$ \\
\hline
\end{tabular}

* Data source: Shandong Statistic Yearbook

\section{THE PERFORMANCE EVALUATION OF SHANDONG PROVINCE'S GOVERNMENTAL FINANCIAL INVESTMENT IN SCIENCE AND TECHNOLOGY}

\subsection{Methodology}

The analysis of the effectiveness of production actions refers to the analysis which aims to seek countermeasures to overcome the ineffectiveness of production actions by studying the efficiency of production decision-making units. Generally speaking, there are two ways to perform such analysis, namely, parametric and non-parametric methods. Regarding the parametric method, researchers first of all assume an input-output function, and use regression analysis to evaluate the parameters of the expression on the basis of a group of input-output data and by meeting a series of assumption conditions. As for the non-parametric method, researchers don't have to assume some concrete input-output functions, and instead rely on mathematical programming as the instrument and input \& output data of the e production decisionmaking units to obtain the evaluation of corresponding efficiency.

As a non-parametric evaluation technique, DEA uses envelop line in place of the production function of macroeconomics to identify the optimum points through mathematical programming, and connects 
the optimum points through a broken line and accordingly forms an envelop line along the efficiency frontier, and then projects the input-output relationship of decision-making organizations on the space to look for the boundary point. The performance evaluation of governmental financial investment in science and technology comprises the impact of such investment on science and technology advance, economic growth and social development. It is rather difficult to determine a definite function expression, and therefore, the author of the paper adopted the non-parametric DEA technique to carry out performance evaluation of Shandong province's governmental financial investment in science and technology.

\subsection{The construction of indexes}

The author identified the input-output performance evaluation indexes of governmental financial investment in science and technology. Meanwhile, the author referred to relevant research home and abroad, and took the factors whether various index data could be obtained, stable or necessary into consideration. In the course of designing, the author followed the train of thought of input-outputachievement. For the input indexes, we selected Shandong province's governmental financial budget expenditure in science and technology and the fulltime equivalent of $\mathrm{R} \& \mathrm{D}$ personnel of the whole province. As for the output indexes, the author selected the quantities of search tools, retrieved papers, the quantities of science and technology achievements, the turnover of technology contracts as well as the quantities of patent applications. See Table 3 for the details:

Table3 The Index System of the Performance Evaluation of Shandong Province's Governmental Financial Budget Expenditure in Science and Technology

\begin{tabular}{|l|l|c|}
\hline Category & Concrete index & Variable \\
\hline \multirow{5}{*}{ Input index } & $\begin{array}{l}\text { Shandong province's governmental } \\
\text { financial budget expenditure in } \\
\text { science and technology }\end{array}$ & $\mathrm{X} 1$ \\
\cline { 2 - 3 } & $\begin{array}{l}\text { The full-time equivalent of R \& D } \\
\text { personnel in Shandong province }\end{array}$ & $\mathrm{X} 2$ \\
\hline & $\begin{array}{l}\text { Domestic and international search } \\
\text { tools \& the quantities of retrieved } \\
\text { papers }\end{array}$ & $\mathrm{Y} 1$ \\
\cline { 2 - 3 } Output index & $\begin{array}{l}\text { The quantities of Shandong } \\
\text { province's science and technology } \\
\text { achievements }\end{array}$ & $\mathrm{Y} 2$ \\
\cline { 2 - 3 } & $\begin{array}{l}\text { The turnover of technology market } \\
\text { contracts }\end{array}$ & $\mathrm{Y} 3$ \\
\cline { 2 - 3 } & The quantities of patent applications & $\mathrm{Y} 4$ \\
\hline
\end{tabular}

The data above were relevant data between 1998 and 2012 taken from China Statistical Yearbook on Science and Technology as well as Shandong Province's Statistical Report.

\subsection{Efficiency analysis}

While analyzing the performance evaluation of governmental financial investment in science and technology, we considered the time lag existing between input and output in science and technology undertakings. Therefore, the time la for the paper here is assumed to be one year. Specifically speaking, the input index data fell between 1998 and 2011 while the output index data fell between 1999 and 2012.

Software deap2.1 was used to substitute input and output data into operation. In this paper, the output was assumed to be dominant, in other words, the maximum value was calculated against the established input. Scale efficiency allowed alteration. Then, the comprehensive efficiency (crste), pure technology efficiency (vrste) and scale efficiency of Shandong province's governmental financial investment in science and technology over years were under investigation respectively. Pure technology efficiency (vrste) was used to observe whether investment in science and technology was redundant or insufficient, and to measure whether the input or the output was optimum. Scale efficiency (scale) was used to observe how output would alter if investment in science and technology increased, and to measure the increase of input and output. IRS/DRS reflected whether in the current state the scale benefit increased, remained unchanged or declined. IRS refers to the increase of scale benefit, indicating that the increase speed of output would be higher than that of input along with the increase of input in science andtechnology. DRS refers to the decline of scale benefit, indicating that output would increase at a speed lower than that of input, while - indicated the unchanged state of scale benefit, namely, the state in which the increase speed of output and that of input were the same.

Table4 The Results of Performance Evaluation of Shandong province's Governmental Financial Investment in Science and Technology

\begin{tabular}{|c|c|c|c|c|}
\hline firm & crste & vrste & scale & irs/drs \\
\hline 1998 & 1.000 & 1.000 & 1.000 & - \\
\hline 1999 & 1.000 & 1.000 & 1.000 & - \\
\hline 2000 & 0.898 & 0.926 & 0.970 & irs \\
\hline 2001 & 1.000 & 1.000 & 1.000 & - \\
\hline 2002 & 0.736 & 0.887 & 0.830 & drs \\
\hline 2003 & 0.929 & 1.000 & 0.929 & drs \\
\hline 2004 & 1.000 & 1.000 & 1.000 & - \\
\hline 2005 & 1.000 & 1.000 & 1.000 & - \\
\hline 2006 & 0.990 & 1.000 & 0.990 & irs \\
\hline 2007 & 1.000 & 1.000 & 1.000 & - \\
\hline 2008 & 0.870 & 0.914 & 0.952 & drs \\
\hline 2009 & 0.985 & 1.000 & 0.985 & drs \\
\hline 2010 & 1.000 & 1.000 & 1.000 & - \\
\hline 2011 & 0.999 & 1.000 & 0.999 & drs \\
\hline
\end{tabular}


From Table 4, we can see, in terms of scale benefit, the technology efficiency and scale efficiency of Shandong province's governmental financial investment and expenditure in science and technology were equal to 1 in the years of 1998 , 1999, 2001, 2004, 2005, 2007, and 2010. It should be interpreted that as governmental financial investment in science and technology expanded, science and technology output tended to be relatively effective and the relatively effective decisionmaking units accounted for $50 \%$ of the overall number. In the relatively ineffective years of 2000 and 2006, the output performance evaluation was that scale benefit increased by degrees, which indicated that if governmental financial investment in science and technology increased, output would increase too until the relationship between the input and the output reached the most optimal state. In the years of 2002, 2003, 2008, 2009, and 2011, the scale benefit decreased by degrees, which indicated that the governmental financial investment in science and technology reached a saturated scale while the corresponding science and technology output were not enough. If governmental financial investment in science and technology continued to increase, its output would increase at a speed lower than that of investment. This fully explains that over these years, governmental financial investment in science and technology has not created the best effect, and therefore if input is properly moderated, the efficiency may increase in turn.

In terms of technology efficiency, expect for the years of 2000, 2002, and 2008, the technology efficiency in the remaining years was 1, which indicated that the technology efficiency reached the most optimal state during those years.

\section{CONCLUSIONS}

Based on the above analysis, the author reached the following conclusions:

1) Shandong provincial government should strengthen its investment in science and technology

The review of relevant domestic and international literature reveals that there exists an apparent positive correlation between investment in science and technology and economic growth. However, the proportion of governmental financial investment in science and technology in Shandong province has remained rather low. Therefore, the government is advised to strengthen such investment if it is to make sure that its economy can develop in a sound and rapid manner.

2) The performance evaluation of Shandong province's investment in science and technology is effective in general.

During the DEA, the technology efficiency of decision-making units is used to measure whether input or output is optimum, whether there is redundancy or insufficiency of investment. Scale benefit, on the other hand, is used to measure the increase of input and output, in other words, if investment increases, how will the output change? The progressive increase of scale benefit refers to the increase of investment in science and technology and its output will increase at a speed higher than that of investment. The decline of scale benefit means that the increase speed of output is lower than that of investment.

The results of analysis tell us that the number of decision-making units that are technically effective is 11 , which accounts for $78.5 \%$ of the total. The number of decision-making units that keep the scale benefit unchanged is 7 , which accounts for $50 \%$ of the total. Therefore, the performance evaluation of Shandong province's investment in science and technology is effective in general.

3) Science and technology output remains to be improved.

The results of the analysis of performance evaluation tell us that among the seven decisionmaking units whose scale efficiency is relatively ineffective, there are five units whose scale benefit decreases by degrees, which accounts for $71.43 \%$ of the total. This indicates that over these years the increase speed of science and technology output is lower than that of science and technology investment, and in other words, science and technology output is relatively insufficient.

\section{ACKNOWLEDGEMENT}

Shandong Province's Soft Science Project of 2013. NO.2013RKB01137.

\section{REFERENCES}

[1] Solow R.M. Technical: change and the aggregate production. Review of Economics and Statictics. 1957

[2] Paul Romer M. Increasing return and long-mn growth. Joumal of Political Economy,1986 (94)

[3] Griliches, Z. Productive, R\&D and Basic Research at the Firm Level in the 1970's. American Economic Review, 76(1)

[4] Hall, B.H. and J.Mairesse, Exploring the relationship between R\&D and productivity in French manufacturing firms Journal of Econometrics

[5] Nadiri, M.I. and T.P. Mamuneas, The effects of public infrastructure and R\&D capital on the cost structure and performance of US manufacturing industries. Review of Economics and Statistics, Vol. XXVI (1): 22-37

[6] Aghion Philippe, Howitt Peter (1992), A Model of Growth through Creative Destruction, Econometrica, Econometric Society, vol. (02): 323-510

[7] Jones C. R\&D - Based Models of Economic Growth. Journal of Political Economy,1995 (103): 759-784

[8] Segerstrom P. (2000), The Long-run Growth Effects of R\&D Subsidies, Journal of Economic Growth Sep2000, VoL5,1ss3: 277

[9] Zhang Shujuan. The research review on Performance Evaluation of Governmental Financial Investment in Science and Technology. Journal of China Business. 2010(11) 